\title{
Method for Evaluating the Digital Potential of a Backbone Innovative Active Industrial Cluster
}

\author{
Larissa Tashenova ${ }^{1,2^{*}}$, Aleksander Babkin ${ }^{1}$, Dinara Mamrayeva ${ }^{2}$, Ivan Babkin ${ }^{1}$ \\ IInstitute of Industrial Management, Economics and Trade, Graduate School of Industrial Economics, Peter \\ the Great St. Petersburg Polytechnic University, Polytechnicheskaya Str., 29, St. Petersburg 195251, Russia \\ ${ }^{2}$ Faculty of Economics, Marketing Department, Y.A. Buketov Karaganda University, Universitetskaya Str., 28, \\ Karaganda 100028, Kazakhstan
}

\begin{abstract}
Issues of digitalizing industrial enterprises and clusters in the formation of Industry 4.0 garner considerable attention. Here, the discussion is about backbone innovative active industrial enterprises, whose appearance is thanks to the evolutionary development of integrated industrial structures, and which are able to actively create, introduce, and commercialize innovative products and to use all the advantages of industrial automation. The authors attempt to develop a method for assessing the digital potential of backbone innovative active industrial clusters. The method is developed based on existing methods for and approaches to evaluating the innovation potential of industrial clusters and the digital potential of industrial enterprises, and makes it possible to calculate a final integral assessment, which includes calculating for each of the seven sub-potentials the parameters identified by experts to be important. In order to confirm the validity of the obtained results, the calculation is carried out using three methods: arithmetic mean, harmonic mean, and weighted geometric mean. The suggested method was successfully tested on the example cluster "Development of information technologies, radio electronics, instrumentation, communication and info-telecommunication devices of St. Petersburg."
\end{abstract}

Keywords: Backbone innovative active industrial cluster; Digital economy; Digital potential; Evaluation method; Innovation

\section{Introduction}

The current era of economic development has seen digital technology and the internet significantly transform many manufacturing, logistical, and technological business processes, models and structures. Below is a brief review of publications on the research topic.

Several authors have examined the role of the development of information technology in forming so-called Enterprise 4.0, whose activities are based on the active use of digitalization tools (Moreira et al., 2018). Some works pay special attention to the issues of forming a regional innovation environment, where the questions of developing an ICT sphere play just as important of a role (Rodionov and Rudskaya, 2017). These authors note the importance of issues regarding management in the structure of a synergistic paradigm, which, in turn, are necessary for creating sustainable organizational and economic systems for managing the innovative and digital potential of industrial enterprises and clusters (Babkin et al., 2017). 
Works addressing these issues as they relate to the service sector include, for example, research dedicated to the development of the tourism industry and tourism clusters looking at issues of developing a sharing economy in the structure of urban tourism (Mamrayeva and Tashenova, 2017). Prior research also points out the importance of using digital tools when forming effective marketing channels for promoting the goods and services of small and medium businesses (Taiminen and Karjaluoto, 2015; Rahmatin et al., 2018).

Certainly, the development of a worldwide digital economy has led to the creation of an array of information dedicated to various areas of science addressing related problems. For example, in one of his works Bataev analyzes the stages of making and developing a digital economy (Bataev, 2018). A report from the United Nations Conference on Trade and Development, presented in 2019 and dedicated to the main aspects of developing a digital economy, notes the opportunity countries have to use digital data and platforms (UNCTAD, 2019). The work "Industry 4.0: Building the Digital Enterprise" examines promising opportunities for building digital enterprises in conditions referred to as the Fourth Industrial Revolution (Industry 4.0) (Geisbauer et al., 2016). Similar scientific aspects are also reflected in other several scientific works (Bazzoun, 2019; Sutherland and Jarrahi, 2018).

In recent years, research has tackled aspects of technological modeling of the manufacturing process, resource planning of a business based on the wide use of computer technology, cloud storage, and the Internet of Things (Mourtzis et al., 2015). Other scientists have paid special attention to the industrial Internet of Things and, as a whole, issues of digital transformation, while a certain emphasis has been placed on the barriers that can prevent effective informatization and creating Nature 5.0 (Berawi, 2020). Other work takes a broad look at promising areas for introducing and using blockchain technology, as well as problems on the road to the automatization and digitalization of manufacturing, including for industrial enterprises (Babkin et al., 2018; Kudryavtseva et al., 2020). It is important to note that the use of digital tools has been studied not only in the manufacturing activities of industrial enterprises, but also in logistics, marketing (Semenov et al., 2018; Karjaluoto et al., 2015), design (Davies, 2015; Demidenko et al., 2018), in reaching target indicators and key business goals (Nylén and Holmström, 2015), and in building effective digital business strategies able to function in the conditions of Industry 4.0 (Bharadwaj et al., 2013). The formation of integrated structures, including the industrial clusters presented here, is the result of many economic transformations and an understanding of the role of such kinds of associations from the management side of industrial enterprises (Novikov and Babkin, 2014). The concept of a cluster was first introduced by M. Porter, who defined the term "cluster" as a "group of geographically adjacent interactive companies and the organizations relating to them, acting in a specific field and complementing each other" (Porter, 1998).

In general, a "backbone innovative active industrial cluster" (BIAIC) is defined as follows: "This is a group of economic subjects of various areas of activity (research, engineering, manufacturing, and others), developing, possessing, and putting into practice globally competitive technology, based on which systematic inter-sectoral (or, at the very least, sectoral) development is ensured, which allows the goals given above to be achieved by using already existing and introduced digital information platforms, transitioning to new models and forms of conducting business and effectively using innovation projects not taken separately but combined in a way effective for the economy, including the sector, region and cluster" (Tashenova and Babkin, 2017; Babkin and Tashenova, 2019).

Taking into account the specifics of cluster activities of this kind (operating on digital platforms with active use of various digital tools), the issue of evaluating its digital potential becomes especially relevant. It is important to note that the digital potential of BIAIC should 
be understood as "the combined total of various sub-potentials (logistical, scientific, organizational and managerial, infrastructure, financial and economic, staff, and information and telecommunications), which should reflect two aspects of cluster activity: its possibility and capacity" (Babkin and Tashenova, 2020a).

At the same time, other authors of scientific articles have evaluated some criteria differently, or assessed the digital potential of individual industrial enterprises or industrial organizations, but not integrated structures such as the presented clusters (Kozlov and Teslya, 2019).

Some authors define digital potential as "the combined total of the data itself, software, and technical devices for its storage and processing and for the personnel using this data for management" (Popov and Semyachkov, 2017).

Several articles do not give a clear definition of the concept of "digital potential." In a 2017 article, however, Kovalchuk and Alekseev write that they understand it as the "assessment monitoring of the indicators of a digital infrastructure and the general structural trends of geolocations" (Kovalchuk and Alekseev, 2017). Yet other researchers consider digital potential in terms of the most important component for the development of the world's regions, particularly Europe (these authors also point out that Europe realizes only $12 \%$ of its digital potential) (Bughin et al., 2016).

The lack of a methodological base determines the need to create a complex quantitative methodology to assess the level of digital potential (DP) of BIAICs based on a selection of various methods, tools, techniques, procedures, and operations. In our earlier studies it was noted that we had not identified any works dedicated to and directly related to the method of assessing the DP of BIAICs; at the same time, a significant number of publications were discovered which were focused on determining the level of innovation potential of industrial enterprises (Babkin et al., 2013; Konkina et al., 2019).

Our methodology for assessing the digital potential of a backbone innovative active industrial cluster is developed based on an understanding of the unique features of using a specific set of methods, combination of stages, and algorithms for evaluating digital potential. Thus, it is important to note the specifics of the research object in question: the digital potential, appearance, and measurement of which are complex and multi-faceted in nature. Consequently, based on the assessment of the DP of a backbone innovative active industrial cluster, the authors propose using an aggregate of seven sub-potentials, including 75 parameters (at the initial stage; and 32 parameters after conducting an expert evaluation and checking it according to the reliability criterion) (Babkin et al., 2019).

\section{Methods}

In the studies we have conducted to assess digital potential, we have substantiated the use of two types of methods: the method of expert evaluation and mathematical statistics. Our previous articles, which can be found in the list of references, have already partially presented the methods that we use in the framework of this scientific article (Babkin and Tashenova, 2020b). The use of these methods was due to the peculiarities of the object and the research procedure.

\subsection{Method of Expert Evaluation when Selecting the Most Important Parameters to Include in the Sub-potentials}

Taking into account the lack of research into the digital potential of BIAICs, the researchers and experts required a significant amount of time to become familiar with each of the factors and to identify its importance within each sub-potential, since it was necessary to determine, with consideration of the specifics of the economic phenomenon 
being studied, what in fact has/may have significant impact on the amount of digital potential, especially in the framework of an integrated structure represented by a backbone innovative active industrial cluster.

A brief characterization of the expert survey conducted follows:

1. period of survey: July-September 2019;

2. number of experts surveyed: 40 people - scientists (university teaching staff, representatives of research institutes, consulting companies), representatives of state structures, clusters, St. Petersburg Center of Cluster Development;

3. for the research, a standardized questionnaire was used, where each parameter was given a point on a scale from 1 to 10 ;

4. the questionnaire was presented both in paper form (distributed "in person") and as an online form created in the program Google Forms (sent out among a specific circle of experts as an internet link).

Experts were asked to rank the factors using the following scale: "insignificant," "hardly significant," "factors bearing significance," and "very significant factors." Next, the ranges for evaluation were determined, both for each of the sub-potentials and for overall potential (Table 1). The evaluation step was 1.21; it was calculated according to Equation 1:

$$
x=\frac{\max -\min }{n}
$$

where $n$ is the number of assessment levels (in this case $n=4$ ).

Table 1 Consolidated table of assessment levels based on the analysis of the steps and ranges of evaluations in terms of the sub-potentials

\begin{tabular}{lc}
\hline \multicolumn{1}{c}{ Assessment level } & Range (evaluation step - 1.22) \\
\hline Level 1: Insignificant factors & $4.63 \leq \mathrm{x} \leq 5.85$ \\
Level 2: Hardly significant factors & $5.86 \leq \mathrm{x} \leq 7.08$ \\
$\begin{array}{l}\text { Level 3: Factors bearing } \\
\text { significance (but minor) }\end{array}$ & $7.09 \leq \mathrm{x} \leq 8.31$ \\
Level 4: Very significant factors & $8.32 \leq \mathrm{x} \leq 9.54$ \\
\hline
\end{tabular}

Next, by using the identified ranges, 32 parameters were obtained for the 7 subpotentials that best reflect the essence of the complex approach used in this work.

2.2. Methods of Mathematical Statistics, Particularly Kendall's Concordance Coefficient, were Used to Confirm the Reliability of the Obtained Results (Kendall, 2008; Lani, 2010)

This coefficient helps determine the degree of expert agreement when making an evaluation. The general formula for calculating the coefficient is:

$$
W=\frac{12 S}{m^{2}\left(n^{3}-n\right)}
$$

where $m$ is the number of experts in the groups; $n$ is the number of factors; and $S$ is the sum of squared differences of ratings.

At the same time, it should be mentioned that if $\mathrm{W}<0.3$ then the agreement of the opinions of the experts presented in the research is unsatisfactory; when $0.3<\mathrm{W}<0.7$ the agreement is average; and if the calculated Kendall's coefficient exceeds a value of 0.7 , then 
there is a high level of agreement among the experts. Results can be taken into account from W values of 0.4 and up.

In this work, Kendall's coefficient was calculated using the program Statistica 6.0. During the final stage, the function "Friedman ANOVA Kendall's concordance" was used to obtain the value of the desired Kendall's concordance coefficient, which in this case is equal to 0.5 , which means an average agreement of expert opinion.

\section{Results and Discussion}

Within the proposed method, the authors further determined the methods for calculating and obtaining any indicators within the sub-potentials.

The next stages of the method for assessing the DP of a BIAIC are looked at below:

- Bringing the obtained values to a single system of measurement. The process is carried out by dividing the practically obtained indicator by the reference value. In this way, relative values independent of the units of measurement are obtained.

- Determining the weighting factors. In the opinion of the authors, the optimal option for determining the weighting factors for sub-potentials at this step is to use Fishburne's formula (Keller and Warwick, 1997; Kotz et al., 2006) with the following equation:

$$
C_{j}=\frac{2(y-j+1)}{y(y+1)}
$$

where $y$ is the number of analyzed sub-potentials and $j$ is the number (ranking) of the subpotential.

By using the obtained formula, as well as the results of expert evaluations obtained during the research, the following weighting factors were calculated: Financial and economic: 0.25; Information and telecommunications: 0.21; Staff: 0.18; Scientific: 0.14; Infrastructure: 0.11; Logistical: 0.07; Organizational and managerial: 0.04 .

- Calculation of the integral indicator for each of the sub-potentials in consideration of the weighting factors obtained earlier (based on expert interviews). The integral indicator for each of the sub-potentials can be calculated using the equation:

$$
G_{j}=\frac{\sum_{j=1}^{m} \alpha_{j}}{m}
$$

where $G_{j}$ is the integral indicator of the sub-potential; $\alpha_{i j}$ is the relative values forming the sub-potential; and $m$ is the sum of the relative values included in the sub-potential.

- Calculation of the total integral indicator of the digital potential of the backbone innovative active industrial cluster, which is the weighted average of the integral indicators for each group of sub-potentials included in the evaluation. Three models of calculation are considered optimal:

1) by using the weighted arithmetic mean:

$$
G=\sum_{j=1}^{m} G_{j} * \beta_{j}
$$

where $G_{j}$ is the integral indicator of the $j$-th group of criteria of the chosen sub-potentials; $\beta_{j}$ is the weight of the $j$-th group of indicators within the blocks of sub-potentials; and $m$ is the number of groups/blocks of sub-potentials with indicators.

The formula for calculating the total integral indicator in consideration of the identified sub-potentials has the following form:

$$
G_{D P_{-} B I A I C}=G_{1} \beta_{1}+G_{2} \beta_{2}+G_{3} \beta_{3}+G_{4} \beta_{4}+G_{5} \beta_{5}+G_{6} \beta_{6}+G_{7} \beta_{7}
$$

where $G_{1}$ is the financial and economic sub-potential; $G_{2}$ is the information and 
telecommunications sub-potential; $G_{3}$ is the staff sub-potential; $G_{4}$ is the scientific subpotential; $G_{5}$ is the infrastructure sub-potential; $G_{6}$ is the logistical sub-potential; and $G_{7}$ is the organizational and managerial sub-potential.

Taking into account the weighting factors calculated for the sub-potentials, the formula takes the following equation:

$$
G_{\text {DP_BIAIC_1 }}=0.07 G_{1}+0.25 G_{2}+0.14 G_{3}+0.04 G_{4}+0.18 G_{5}+0.21 G_{6}+0.11 G_{7}
$$

2) by using the weighted geometric mean (where the calculation of the integral indicator of the $j$-th group of criteria of the selected sub-potentials is based on Equation 5):

$$
G_{\text {DP_BIAIC_2 }}=\sqrt{G_{1}^{0,07} * G_{2}^{0,25} * G_{3}^{0,14} * G_{4}^{0,04} * G_{5}^{0,18} * G_{6}^{0,21} * G_{7}^{0,11}}
$$

3) by applying the formula for calculating the weighted harmonic mean (where, as in case 2, the calculation of the integral indicator of the $j$-th group is also based on Equation 5):

$$
G_{\text {DP_BIAIC_3 }}=\frac{1}{\frac{0,07}{G_{1}}+\frac{0,25}{G_{2}}+\frac{0,14}{G_{3}}+\frac{0,04}{G_{4}}+\frac{0,18}{G_{5}}+\frac{0,21}{G_{6}}+\frac{0,11}{G_{7}}}
$$

Based on the resulting evaluation, the level of the digital potential of a backbone innovative active industrial cluster is determined.

It is proposed to "spread" the obtained results for the calculations of the total integral evaluations using Harrington's scale, focusing only directly on the subject of research: very high DP (0.81-1.0); high DP (0.64-0.8); above-average DP (0.37-0.63); average DP (0.2$0.36)$; low / no DP $(0.0-0.19)$.

The final stage is the development of recommendations for increasing / maintaining the level of digital potential of BIAICs. At this stage it seems possible to develop a plan of action aimed at increasing the DP level, or at maintaining it if the BIAIC has a very high level of digital potential.

In general, the method for evaluating the digital potential of a backbone innovative active industrial cluster is presented in Figure 1.

The method developed by the authors for evaluating the DP of BIAIC is complete and complex. This method was successfully tested on the example of the cluster "Development of information technology, radio electronics, instrumentation, communication, and info telecommunication devices of St. Petersburg." The calculated values of the integral values for the sub-potentials of the analyzed cluster are as follows: "Logistical" - 0.21; "Financial and economic" - 0.71; "Scientific" - 0.52; "Organizational and managerial" - 0.47; "Staff" 0.36; "Information and telecommunications" - 0.93; "Infrastructure" - 0.95.

In the opinion of the authors, identification of the infrastructure potential is explained by the organizational component of a BIAIC; at the same time, the importance of the subpotential "Information and telecommunications" is dictated by the specifics of the cluster itself: in this case, the backbone cluster, where the use of ICT tools and digital platforms determines the peculiarities of how industrial clusters of this kind operate and also significantly impacts the formation and future development of their digital potential.

Next, the final integral indicator of the DP of the BIAIC is calculated using the weighted arithmetic mean 0.65 (High DP); using the weighted geometric mean 0.77 (High DP); and using the weighted harmonic mean 0.53 (Above-average DP).

It is important to note that the two calculated indicators fall within the "High DP" range identified above (0.64-0.79) according to a modernized Harrington's scale.

Thus, it can be noted that the method developed by the authors for evaluating the digital potential of a backbone innovative active industrial cluster works without any gross errors or mistakes. 


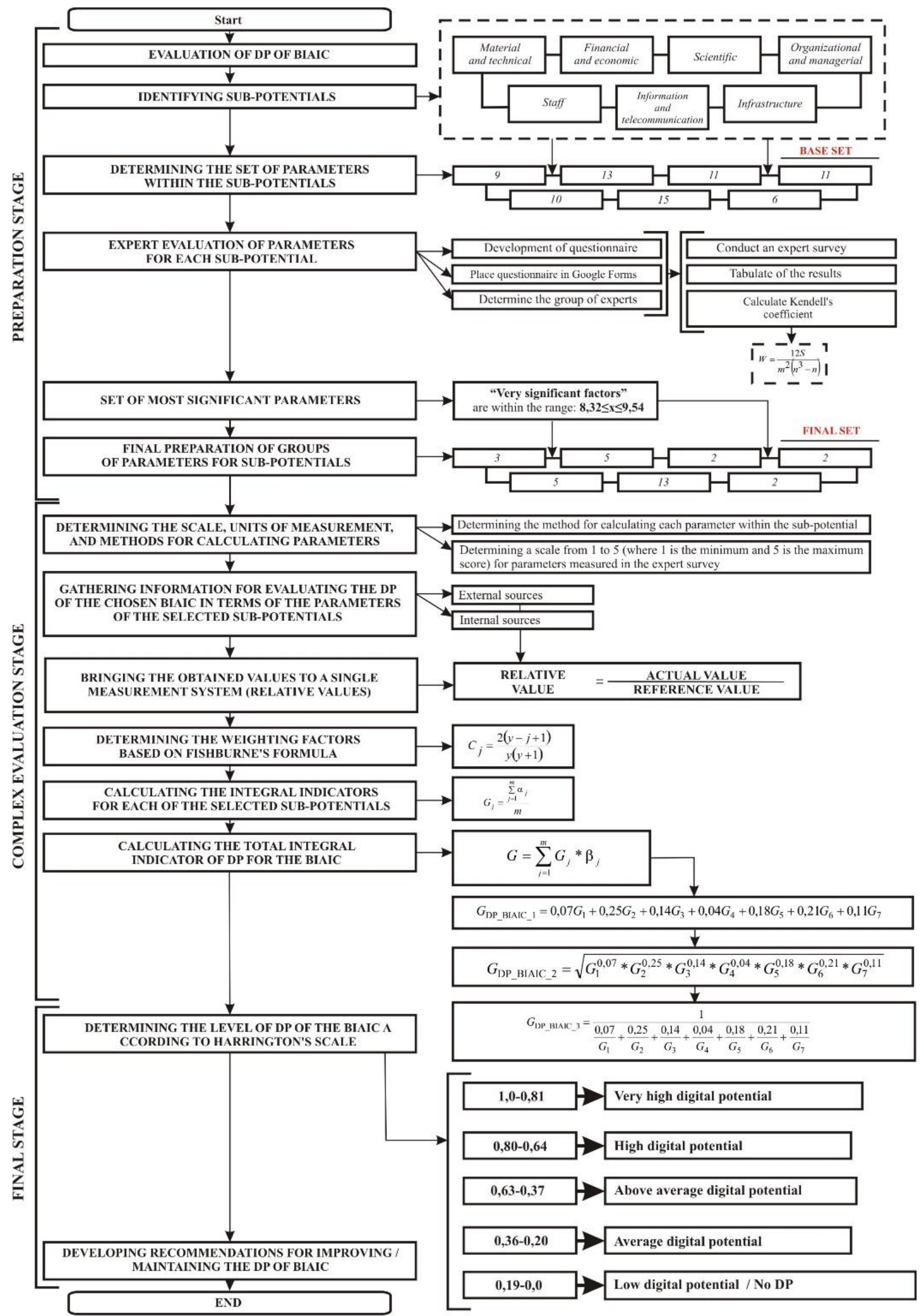

Figure 1 Method for evaluating the digital potential of a backbone innovative active industrial cluster 


\section{Conclusions}

The method presented here allows for an evaluation of the current digital potential of a backbone innovative active industrial cluster; at the same time, it seems practically impossible and, in the authors' opinion, incorrect to make assessments for the long term, since the digital component of the activity of any industrial enterprise, and all the more that of a complex integrated structure, is subject to frequent changes due to the development, constant improvement, and appearance of new digitalization tools, again underlining the need to reexamine the components of digital potential within specific time periods.

It is important to mention that the evidence on the current state of the digital potential of BIAICs basing their activities on digital platforms is, practically, one of the keys to forming the right set of management solutions.

\section{Acknowledgements}

This research work was supported by the Academic Excellence Project 5-100 proposed by Peter the Great St. Petersburg Polytechnic University.

\section{References}

Babkin, A., Kudryavtseva, T., Utkina, S., 2013. Formation of Industrial Clusters using Method of Virtual Enterprises. Procedia Economics and Finance, Volume 5, pp. 68-72

Babkin, A., Tashenova, L., Mamrayeva, D., Azimov, P., 2019. Development of Algorithm to Measure Digital Potential of High-tech Industrial Cluster. In: ACM International Conference Proceeding Series, October 24-25 2019, Saint-Petersburg, Russia, pp. 1-7

Babkin, A.V., Burkaltseva, D.D., Betskov, A.V., Kilyaskhanov, H.S., Tyulin, A.S., Kurianova, I.V., 2018. Automation Digitalization Blockchain: Trends and Implementation Problems. International Journal of Engineering \& Technology, Volume 7(3), pp. 254-260

Babkin, A.V., Tashenova, L.V., 2019. Backbone Innovative-Active Industrial Cluster: Genesis Development. In: Digital Transformation of Economy and Industry (DTEI) 2019, June 20-22 2019, Saint-Petersburg, Russia, pp. 180-191

Babkin, A.V., Tashenova, L.V., 2020a. Conceptual Model of the Organizational-Economic Mechanism for Managing the Digital Potential of a System-Forming Innovative-Active Industrial Cluster. Natural and Humanitarian Research, Volume 6(3), pp. 58-63

Babkin, A.V., Tashenova, L.V., 2020b. Evaluation Stages of Digital Potential of an InnovativeActive Industrial Cluster of the Arctic Zone of Russia. St. Petersburg State Polytechnical University Journal. Economics, Volume 13(5), pp. 65-81

Babkin, A.V., Tashenova, L.V., Chuprov, S.V., 2017. Management of Sustainability and Development of Systems in the Context of the Synergetic Paradigm. In: Proceedings of 2017 IEEE, 2nd International Conference on Control in Technical Systems (CTS) 2017, October 25-27 2017, Saint-Petersburg, Russia, pp. 318-321

Bataev, A.V., 2018. Analysis and Development the Digital Economy in the World. In: Proceedings of the $31^{\text {st }}$ International Business Information Management Association Conference (IBIMA) 2018, 25-26 April 2018, Milan, Italy, pp. 61-71

Bazzoun, M., 2019. The Digital Economy. International Journal of Social Science and Economics Invention, Volume 5(9), pp. 116-118

Berawi, M.A., 2020. Managing Nature 5.0: The Role of Digital Technologies in the Circular Economy. International Journal of Technology, Volume 11(4), pp. 652-655

Bharadwaj, A., El Sawy, O.A., Pavlou, P.A., Venkatraman, N., 2013. Digital Business Strategy: Toward a Next Generation of Insights. MIS Quarterly, Volume 37, pp. 471-482

Bughin, J., Hazan, E., Labaye, E., Manyika, J., Dahlström, P., Ramaswamy, S., Cochin de Billy 
C., 2016. Digital Europe: Realizing the Continent's Potential (Report). Available Online at: $\quad$ https://www.mckinsey.com/business-functions/mckinsey-digital/ourinsights/digital-europe-realizing-the-continents-

potential\#: :text=Europe $\% 20$ is\%20operating\%20below\%20its,in\%20less $\% 20$ than $\% 20 a \% 20$ decade, Accessed on September 14, 2020

Davies, R., 2015. Industry 4.0. Digitalisation for Productivity and Growth (Briefing). Available Online at: https://www.europarl.europa.eu/thinktank/en/document.html?reference=EPRS_BRI \%282015\%29568337, Accessed on September 19, 2020

Demidenko, D.S., Malevskaia-Malevich, E.D., Dubolazova, Y.A., Victorova, N.G., 2018. Optimization of the Innovation Process Management at a Manufacturing Enterprise. In: Proceedings of the $31^{\text {st }}$ International Business Information Management Association Conference (IBIMA) 2018, 25-26 April 2018, Milan, Italy, pp. 996-1003

Geisbauer, R., Vedso, J., Schrauf, S., 2016. Industry 4.0: Building the Digital Enterprise. Report PwC, Research and Insight, PwC. Available Online at: https://www.pwc.com/gx/en/industries/industries-4.0/landing-page/industry-4.0building-your-digital-enterprise-april-2016.pdf, Accessed on October 19, 2020

Karjaluoto, H., Mustonen, N., Ulkuniemi, P., 2015. The Role of Digital Channels in Industrial Marketing Communications. Journal of Business \& Industrial Marketing, Volume 30(6), pp. 703-710

Keller, G., Warwick, B., 1997. Statistics for Management and Economics. The Journal of the Operational Research Society, Volume 48(9), pp. 963-964

Kendall, M.G., 2008. Kendall Rank Correlation Coefficient. In: The Concise Encyclopedia of Statistics. Available Online at: https://link.springer.com/referenceworkentry/10.1007\%2F978-0-387-328331_211, Accessed on September 21, 2019

Konkina, V., Shemyakin, A., Babkin I., 2019. Information and Software of Managing the Industry Cluster of the Region. In: Proceedings of the 33 ${ }^{\text {rd }}$ International Business Information Management Association Conference (IBIMA) 2019, 10-11 April 2019, Granada, Spain, pp. 8632-8637

Kotz, S., Read, C.B., Balakrishnan, N., Vidakovic, B., Johnson, N.L., 2006. Review of Economics and Statistics. In: Encyclopedia of Statistical Sciences, Kotz, S., John Wiley \& Sons, Inc, New Jersey, USA

Kovalchuk, Y.A., Alekseev, I.V., 2017. The Digital Potential of Regional Markets as a New Strategic Factor in the Development of Franchise Businesses. Bulletin of the South Ural State University. Series. Economics and Management, Volume 2(11), pp. 149-158

Kozlov, A., Teslya, A., 2019. Digital Potential of Industrial Enterprises: Essence, Determination and Calculation Methods. Bulletin of ZabGU, Volume 29, pp. 101-110

Kudryavtseva, T., Kulagina, N., Lysenko, A., Berawi, M.A., Skhvediani, A., 2020. Developing Methods to Assess and Monitor Cluster Structures: The Case of Digital Clusters. International Journal of Technology, Volume 11(4), pp. 667-676

Lani, J., 2010. Correlation (Pearson, Kendall, Spearman). Available Online at: http://www.statisticssolutions.com/wp-content/uploads/kalinspdf/singles/correlation-pearson-kendall-spearman.pdf, Accessed on September 22, 2019

Mamrayeva, D., Tashenova, L., 2017. Prospects of Bicycle-Sharing in Urban Tourism in the Republic of Kazakhstan: Myth or Reality? Transport Problems, Volume 12 (2), pp. 6576

Moreira, F., Ferreira, M.J., Seruca, I., 2018. Enterprise 4.0 - The Emerging Digital 
Transformed Enterprise? Procedia Computer Science, Volume 138, pp. 525-532

Mourtzis, D., Papakostas, N., Mavrikios, D., Makris, S., Alexopoulos, K., 2015. The Role of Simulation in Digital Manufacturing: Applications and Outlook. International Journal of Computer Integrated Manufacturing, Volume 28(1), pp. 3-24

Novikov, A.V., Babkin, A.V., 2014. Stages and Tools of Evaluation of Cluster Operation (Case Study of Shipbuilding Cluster of St. Petersburg). Biosciences Biotechnology. Research Asia, Volume 11(3), pp. 1563-1571

Nylén, D., Holmström, J., 2015. Digital Innovation Strategy: A Framework for Diagnosing and Improving Digital Product and Service Innovation. Business Horizons, Volume 58(1), pp. 57-67

Popov, E.V., Semyachkov, K.A., 2017. An Assessment of Readiness of the Branches of Russian Federation for Formation of Digital Economy. Innovatcii, Volume 4, pp. 37-41

Porter, M.E., 1998. Clusters and the New Economics of Competition. Harvard Business Review, Volume 76(6), pp. 77-90

Rahmatin, N., Santoso, I., Indriani, C., Rahayu, S., Widyaningtyas, S., 2018. Integration of the Fuzzy Failure Mode and Effect Analysis (Fuzzy FMEA) and the Analytical Network Process (ANP) in Marketing Risk Analysis and Mitigation. International Journal of Technology, Volume 9(4), pp. 809-818

Rodionov, D.G., Rudskaya, I.A., 2017. Regional Innovative Environment in National Economic Development (The Case of Russia). International Journal of Ecology and Development, Volume 32(4), pp. 20-28

Semenov, V.P., Sokolitsyn, A.S., Sokolitsyna, N.A., 2018. Marketing Activity Management Improvement for Small-Series Production Enterprises. In: Proceedings of the 2018 International Conference "Quality Management, Transport and Information Security, Information Technologies" 2018, September 24-28 2018, Saint-Petersburg, Russia, pp. 382-384

Sutherland, W., Jarrahi, M.H., 2018. The Sharing Economy and Digital Platforms: A Review and Research Agenda. International Journal of Information Management, Volume 43(1), pp. 328-341

Taiminen, H.M., Karjaluoto, H., 2015. The Usage of Digital Marketing Channels in SMEs. Journal of Small Business and Enterprise Development, Volume 22(4), pp. 633-651

Tashenova, L.V., Babkin, A.V., 2017. Backbone Innovation-Active Industrial Cluster in the Conditions of Digital Transformation: Concept, Essence, Features. In: Proceedings of the Scientific and Practical Conference with International Participation: "Economic and Management in the Context of Digitalization: State, Problems, Foresight," December 25 2019, St. Petersburg, Russia, pp. 301-313

United Nations Conference on Trade and Development (UNCTAD): Digital Economy Report, 2019: Value Creation and Capture: Implications for Developing Countries. Available Online at: https://www.un-ilibrary.org/democracy-and-governance/digital-economyreport-2019_c7dc937a-en, Accessed on October 3, 2020 